\title{
A localização residencial em uma cidade vertical: um estudo sintático em Florianópolis
}

\author{
Residential location in a vertical city: a syntactic study in Florianópolis
}

Amanda Carvalho, Renato Tibiriçá de Saboya

Universidade Federal de Santa Catarina (UFSC), Florianópolis, SC, Brasil

\section{Resumo}

Grande parte da dinâmica de crescimento urbano é motivada pela busca do lucro, o qual, por sua vez, está relacionado à localização, principal componente de valorização do solo. A verticalização é uma das estratégias para a maximização do lucro sobre o solo urbano. Em áreas onde o custo deste é alto, os promotores imobiliários tendem a intensificar a área construída e o número de pavimentos. 0 objetivo deste estudo é investigar as características configuracionais das vias em que aconteceu o processo de verticalização residencial em Florianópolis, no Estado de Santa Catarina. Para isso, utilizou-se a Teoria da Sintaxe Espacial, por meio de suas duas medidas principais, Integração e Escolha. Os resultados indicaram que a lógica de localização dos edifícios residenciais verticais (ERVs) na cidade de Florianópolis está relacionada, principalmente, à medida de Escolha local (R3), ou seja, há maior concentração de ERVs em vias que canalizam fluxos utilizados para chegar às outras partes dentro de um sistema local, tornando sua localização localmente central. Entretanto, isso está também relacionado ao processo histórico de ocupação urbana, com áreas mais antigas e consolidadas mostrando tendência de ocupação dos ERVs em vias com maior Integração e Escolha até um determinado momento e posteriormente voltando-se para áreas mais interiorizadas do tecido.

Palavras-chave: Verticalização. Localização residencial. Sintaxe espacial. Características configuracionais.

\section{Abstract}

A substantial portion of urban growth is motivated by profit seeking, which is related to location, the main component of land value. The verticalization is one of the strategies for obtaining larger profits from urban land, since the high cost of land leads developers to increase the number of floors in order to maximize the returns of their investment. The aim of this study is to investigate the configurational characteristics of the streets in which residential verticalization occurred in Florianopolis. In order to do this, we used the theory of Space Syntax and its two main measures, integration and choice. We found that the logic of vertical residential buildings location in Florianopolis is better revealed by local choice measure (R3), that is, there is a greater concentration of vertical residential buildings in streets used to access other parts of the system within a local area. However, this is also tied to the historical process of urbanization, with older and more consolidated areas showing a tendency to occupy its more integrated and higher choice streets up until a certain point in time, and then proceeding to occupy the more interiorized portions of the grid.

Keywords: Verticality process. Residential location. Space syntax. Configurational characteristics.

AC é arquiteta, mestre em Arquitetura e Urbanismo, e-mail: acarvalho.dc@gmail.com RTS é arquiteto, doutor em Engenharia Civil, e-mail: rtsaboya@gmail.com 


\section{Introdução}

0 rápido e intenso processo de crescimento espacial e populacional das médias e grandes cidades brasileiras tem atraído os interesses de uma classe econômica dominante, sobretudo de incorporadoras imobiliárias. Nesse contexto, dentre as diversas formas de reprodução do capital sobre o solo urbano, o processo de verticalização tem sido uma das características mais marcantes e significativas da cidade capitalista, fazendo parte dos interesses de seus agentes e sendo percebida pelo crescimento quantitativo e espacial que acaba alterando a paisagem urbana e a forma de morar do cidadão (Töws \& Mendes, 2011).

Conceitualmente, a verticalização envolve a noção de edifício alto ou arranha-céu. Somekh (1997) a define como a multiplicação do solo urbano, possibilitada pelo uso do elevador, e aponta que a construção dos primeiros arranha-céus na cidade de São Paulo, nos anos 1920, deu início ao intenso processo de modificação urbana que se estende até hoje. Alguns aspectos sobre o processo de verticalização no Brasil podem ser elencados de forma resumida: (1) é uma característica da urbanização brasileira (Mendes, 1992; Souza, 1994); (2) está atrelado à ideia de modernidade (Ramires, 1997, 2011); (3) é caracterizado por uma verticalização mais vinculada à habitação do que serviços, ao contrário do que ocorre em outros países do mundo (Souza, 1994); (4) foi possibilitado por uma revolução na forma de construir, tanto com relação às novas técnicas quanto à utilização de materiais diferenciados, afetando diretamente a dinâmica de acumulação e produção de capital (Somekh, 1997; Ramires, 2011; Töws \& Mendes, 2011); (5) também é tido como responsável por impactos significativos na estrutura urbana, sobretudo social, e no valor e uso do solo urbano (Ramires, 2011); (6) o Estado passa a ter o papel de produtor do espaço urbano, disciplinando seu crescimento por meio das legislações urbanísticas, como zoneamentos, definição de gabaritos de altura, taxas de ocupação e índices de aproveitamento dos lotes (Ramires, 2011; Somekh, 1997); (7) a lógica mercadológica é intrínseca a esse processo (Ramires, 2011; Somekh, 1997; Villaça, 1986; Wheaton, 1982).

Quanto a este último item, Somekh (1997) aponta que essa lógica é resultado da articulação de diversos setores capitalistas. Um deles é o mercado imobiliário, que visa obter, por meio da multiplicação do solo, a máxima valorização do capital, transformando a terra em mercadoria. Nesse sentido, a localização pode ser caracterizada como um dos motores que impulsionam o processo de verticalização e a principal componente de valorização do solo (Gonzales, 1985; Capozza \& Helsley, 1989; Villaça, 1986, 2001): "A terra urbana só interessa enquanto 'terra-localização', ou seja, enquanto meio de acesso a todo o sistema urbano, a toda a cidade" (Villaça, 2001, p. 74).

Dessa forma, a atratividade de certas localizações intraurbanas está relacionada, entre outros fatores: à quantidade e qualidade da infraestrutura existente; à acessibilidade proporcionada ao centro da cidade (na literatura em inglês, ao CBD - Central Business District) e a outros centros secundários de comércios, serviços e empregos; aos atributos ou diferenciações espaciais, como orlas marítimas, proximidade a parques, praças, ou outras amenidades; e a indicações de status e níveis socioeconômicos associados a determinadas localidades da cidade (Gonzales, 1985; Somekh, 1997; Abramo, 2001; Villaça, 2001; Ferreira, 2006; Ramires, 1997).

A escolha da "melhor localização" é feita de forma diferente pelo empreendedor imobiliário e pelo usuário. Para o empreendedor, é aquela que lhe permite extrair maior lucro, não sendo necessariamente a mais acessível ao CDB ou com maior quantidade e qualidade de infraestrutura. Na realidade, as áreas com tais características tendem a ser mais caras e resultam no efeito contrário desejado pelo incorporador (Krafta, 1994). Para o usuário, o dilema da escolha da localização reside em estar próximo ao $\mathrm{CDB}$, onde o custo médio com deslocamento é mais baixo, porém o preço relativo da habitação é elevado, ou escolher áreas afastadas, implicando custo maior com transporte e menor com habitação (Gorter \& Nijkamp, 2001; Abramo, 2001).

Há, portanto, do ponto de vista do empreendedor imobiliário, um tênue equilíbrio entre uma área barata, que diminua o custo da produção e maximize o lucro, por um lado, e uma localização atraente o suficiente para os usuários, por outro. Compreender esse equilíbrio pode auxiliar o entendimento da dinâmica de produção e reprodução urbanas, bem como o papel que a localização exerce sobre ela.

Para isso, uma correta descrição das características de localização é fundamental. Como alternativa mais sofisticada à noção de distância ao CBD, tradicionalmente utilizada em estudos locacionais (veja, por exemplo, Capozza \& Helsley, 1989; Giuliano 
et al., 2010), foram utilizadas neste artigo as análises configuracionais introduzidas pela Teoria da Sintaxe Espacial (Hillier \& Hanson, 1984). Diversos trabalhos empíricos encontraram evidências de que medidas dessa teoria estão fortemente associadas a padrões urbanos relevantes, tais como o uso e valor do solo e, especialmente, os padrões de movimento de pedestres (Hillier \& Hanson, 1984; Hillier et al., 1993; Hillier \& Iida, 2005).

Assim, o objetivo deste estudo é investigar as características locais - sob o viés da configuração - das vias em que aconteceu o processo de verticalização residencial na cidade de Florianópolis, considerando os edifícios residenciais verticais (ERVs) de forma geral e, mais especificamente, segundo as décadas de construção e o número de pavimentos. Para isso, foram utilizadas duas medidas sintáticas diferentes que capturam propriedades distintas da localização, de forma a responder às seguintes questões: Dentro do conjunto total de vias nas quais poderiam aparecer edificações residenciais verticais, em quais elas efetivamente apareceram? Quais são suas características de proximidade e centralidade em relação às demais vias do sistema urbano e àquelas no seu entorno imediato? Nossa hipótese é que essas edificações estariam localizadas em áreas bem integradas, mas com baixa escolha, isto é, próximas aos outros espaços do sistema, sem, entretanto, estar nos caminhos mais utilizados. Isso seria uma maneira de equilibrar a equação entre acessibilidade a bens, pessoas e serviços, por um lado, e o desejo por ambientes tranquilos, sem ruídos e sem a insegurança proporcionada pelo tráfego intenso de veículos, por outro. Para os objetivos deste trabalho, as medidas configuracionais proporcionadas pela Teoria da Sintaxe Espacial podem fornecer meios mais específicos de caracterizar a localização, possibilitando análises mais precisas e com capacidade para distinguir algumas nuances não captadas por medidas de localização fundamentadas em distância ao centro principal.

\section{Localização e produção urbanas}

\section{Dinâmica de crescimento urbano}

Grande parte da dinâmica de crescimento urbano é motivada pela busca do lucro. Este, por sua vez, é diretamente derivado da diferença entre o preço final de venda e o custo da produção da mercadoria imobiliária, incluindo aí não apenas os custos de construção, tais como mão de obra e materiais, mas também as taxas, os impostos, os projetos e, em especial, a terra. Segundo Krafta (1999) e Gonzales (1985), o custo da construção tende a não variar muito dentro de uma determinada área urbana, desde que as construções sendo comparadas possuam níveis similares de acabamento e de complexidade técnica e construtiva. Assim, as maiores variações no preço de imóveis devem-se, ao fim e ao cabo, ao preço pago pela terra. Disso conclui-se que, para maximizar o lucro de um empreendimento imobiliário, a principal estratégia é minimizar o custo do terreno.

Este, por sua vez, é altamente influenciado pela sua acessibilidade a outras partes da cidade (Capozza \& Helsley, 1989; Villaça, 2001). Portanto, áreas mais acessíveis tendem a ser mais caras, pelo fato de: a) minimizarem os custos de deslocamento, por parte daqueles que as ocupam, aos empregos, comércio, serviços e outras amenidades proporcionadas pela cidade; e b) possuírem maior quantidade de trabalho social aplicado no seu entorno, na forma de investimentos públicos em infraestrutura de água e saneamento, transportes etc., e por meio dos investimentos realizados por particulares (outras habitações, comércios etc.).

Isso resulta em um aspecto complexo do processo de desenvolvimento urbano: se, por um lado, os empreendedores gostariam de oferecer a seus compradores as melhores localizações como forma de extrair maiores receitas, por outro sentem a necessidade de oferecer as "piores" localizações como forma de minimizar o gasto com o terreno e, assim, auferir maiores lucros. Krafta $(1994,1999)$ resume essa equação argumentando que os empreendedores compram terrenos mal localizados e os vendem como partes de "novas" - e boas - localizações.

Ainda segundo Krafta $(1994,1999)$, áreas com esse potencial são "descobertas" pelos empreendedores, que nelas constroem e vendem seus produtos imobiliários com lucro. Por serem os pioneiros, auferem grandes lucros, uma vez que o preço da terra ainda é baixo, em um processo similar à inovação tecnológica nas empresas (Harvey, 1985 apud Krafta, 1994), até o ponto em que as vantagens locacionais iniciais tornam-se desvantagens, à medida que o custo da terra aumenta. Outros empreendedores seguem o mesmo caminho em busca de lucros igualmente grandes, mas com 
uma diferença: quando chegam, o preço da terra já não é mais o mesmo. Ele aumentou em função do investimento feito pelo primeiro empreendedor.

0 ciclo se repete com lucros cada vez menores, até que acontece uma de duas possibilidades. A primeira é que, para o investimento valer a pena mesmo com o preço da terra mais alto, é necessário haver uma maior concentração de capital naquela localização. Isso se dá por meio do aumento do nível da construção, passando, por exemplo, de uma residência de classe média para uma de alta classe, ou pelo aumento da relação entre a área construída e a área do terreno, ou seja, a verticalização (Wheaton, 1982; Krafta, 1999).

Outra possibilidade é que, mesmo com a alternativa da intensificação do capital aplicado, não seja mais vantajoso comprar terrenos naquela área. Nesse caso, a relação entre a demanda pela localização e o preço que ela impõe, por um lado, e a possibilidade de explorá-la com novas edificações, por outro, não é atrativa aos potenciais empreendedores naquele momento, os quais optam por abandonar a área em busca de novas e mais atraentes oportunidades. No seu conjunto, esse sistema teórico explica, ao menos em parte, tanto as "ilhas" de dinamismo imobiliário concentradas em alguns pontos específicos da malha urbana como os terrenos vazios deixados em áreas já consolidadas, quando esses focos de investimento são transferidos para outros locais.

\section{Características locacionais}

Diversos bens que atendem às necessidades humanas assumem forma de mercadoria em um dado momento. 0 mesmo ocorre com a habitação, que está diretamente relacionada ao mercado imobiliário. A habitação, enquanto mercadoria, depende de um fator muito importante para se valorizar: a localização. No caso dos usos residenciais, quais seriam os fatores que constituiriam uma boa localização? Quais são os principais aspectos que incidem sobre o valor do solo, tão importante na escolha da localização residencial?

0 primeiro fator que incide sobre o valor do solo é a presença de infraestrutura urbana (Gonzales, 1985; Somekh, 1997), representada pela existência de condições favoráveis à urbanização e de serviços essenciais, tais como asfalto, calçadas, mobiliário urbano, água, luz, saneamento, iluminação etc. Nessa mesma categoria, podem estar incluídos elementos não essenciais, ou mesmo supérfluos, como TV a cabo e internet, entre outros serviços.

Outra infraestrutura urbana essencial, e rotineiramente em debate, é a presença de um sistema de transporte público eficiente. Ao melhorar as condições do sistema viário de certa área ou quando há implantação ou qualificação do sistema de transporte público, essa área tende a tornar-se mais atrativa para instalação de residências, comércios e serviços, valorizando-se e elevando o valor do solo.

Outro fator que influencia o preço da terra é a sua acessibilidade a outros pontos da cidade (Villaça, 2001), entendido especialmente como proximidade ao centro principal e a centros secundários de comércio e serviços, a polos de empregos, a outros bairros, a grandes equipamentos (universidades, shopping centers, universidades etc.) e a outras pessoas (Lynch, 1984; Batty, 2009). Conforme aponta Lefebvre (1974, p. 391 apud Villaça, 2001, p. 73), "0 adquirente é detentor de uma distância, aquela que interliga sua habitação a lugares, os centros de comércio, de trabalho, de lazer, de cultura, de decisão".

A multiplicação do solo urbano também é uma das estratégias para a obtenção de lucro e, portanto, exerce influência sobre o valor do solo por meio da expectativa de maior ou menor potencial de exploração da capacidade construtiva de um terreno. 0 alto valor do solo urbano faz com que muitos empreendedores intensifiquem o número de pavimentos, inserindo no espaço urbano a verticalidade residencial. Como o valor do solo urbano está, em grande parte, condicionado à sua proximidade com o centro principal, o padrão de verticalização resultante tende a ser inversamente proporcional à distância do centro da cidade. Dessa forma, quanto mais próximo ao centro, mais altas seriam as edificações. À medida que se desloca para a periferia, a verticalidade dá lugar a uma configuração residencial mais horizontal (Somekh, 1997; Abramo, 2001; Gonzales, 1985).

Essa diferenciação na possibilidade de construir mais de uma vez a área do terreno está associada primordialmente à legislação territorial municipal, em especial ao Plano Diretor e ao zoneamento de uso e ocupação do solo.

Além desses fatores, a raridade do solo urbano, segundo Gonzales (1985), aliada às qualidades adquiridas por meio do status dos diferentes setores da cidade, transforma o solo urbano em uma mercadoria rara. Sendo assim, essas áreas são 
capazes de produzir empreendimentos com preços superiores ao valor de sua produção, principalmente nas cidades em processo de crescimento significativo. Sob essas condições, a autora afirma que é possível obter a chamada renda de monopólio (RM), fator determinante na medida dos preços do solo urbano. A RM varia segundo o nível da qualidade do empreendimento e do local (como é o caso, por exemplo, de áreas litorâneas), a sua condição de raridade e a capacidade de pagamento dos consumidores. Essa qualidade é atribuída ao lote pelo status, criado "espontaneamente" a partir do crescimento da cidade ou pelo zoneamento, que atribui usos e qualificações especiais às áreas residenciais. Todo o excedente que as condições da localização e do monopólio propiciam sobre o valor da produção do empreendimento é fonte de renda sobre o solo urbano e determinante de seu valor de mercado.

\section{Sintaxe espacial}

A Teoria da Sintaxe Espacial, desenvolvida por Bill Hillier e colegas da University College London (Hillier \& Hanson, 1984), possui como uma de suas principais características a ênfase na importância da relação de um espaço com todos os demais espaços do sistema, além de ter surgido da observação da cidade procurando compreender a dialética entre aspectos físicos e sociais.

Para compreender essa teoria, é importante entender o conceito de Movimento Natural (MN) (Hillier et al., 1993), segundo o qual uma parcela significativa de todos os deslocamentos de pedestres é determinada exclusivamente pela configuração do sistema viário, isto é, apenas pela forma como as vias e demais espaços públicos estão relacionados entre si, sem levar em consideração a localização dos atratores (comércios, serviços, residências, equipamentos urbanos etc.). Segundo Hillier (2007), essa relação entre configuração e movimento é uma força poderosa na conformação das cidades, influenciando aspectos importantes como o uso do solo e as densidades urbanas.

Em virtude da configuração da malha, o MN atribui a certas localidades maior ou menor atratividade para determinados usos e atividades, por estarem em locais com grandes ou pequenos fluxos de pedestres e veículos, gerando, dessa forma, diferentes potenciais de desenvolvimento (construção, reconstrução, densificação, substituição tipológica e de usos etc.) de acordo com sua localização na malha urbana.

A Sintaxe Espacial utiliza técnicas e modelos computacionais para o entendimento das questões configuracionais da malha urbana, associando valores quantitativos e expressões matemáticas para a análise do espaço. Esses procedimentos investigativos geram medidas que têm se mostrado capazes de se correlacionar com os fluxos naturais de movimentação na malha viária, tanto de pedestres como de veículos (Hillier et al., 1993; Penn et al., 1998; Hillier \& Iida, 2005).

Para a análise sintática, a unidade espacial básica são as linhas axiais, entendidas como as maiores linhas retas capazes de cobrir todo o sistema de espaços públicos (Hillier \& Hanson, 1984), representando o sistema viário e conectando-se umas às outras.

Esse modelo proporciona uma série de medidas configuracionais, das quais as mais utilizadas são Integração e Escolha.

A medida de Integração mede o quão próxima uma linha axial está de todas as outras linhas do sistema. Essa proximidade é calculada a partir do número médio de mudanças de direção (chamadas de passos topológicos) necessárias para que todas as outras linhas sejam alcançadas. Dessa forma, Hillier et al. (1993) afirmam que quanto mais espaços intermediários houver entre dois pontos, maior será sua profundidade e, portanto, menor sua Integração. Em resumo, quanto mais próxima (topologicamente) uma linha axial estiver, em média, das outras, mais integrada ela será; em contrapartida, quanto mais distante, mais segregada.

Já a medida de Escolha indica o quanto uma determinada linha axial faz parte do percurso mínimo entre todos os possíveis pares de espaços. Assim, quanto mais essa linha for utilizada como caminho mínimo entre outras linhas, maior será sua medida de Escolha. Essa medida é capaz de captar o movimento através, ou seja, que não foi necessariamente gerado naquele determinado espaço, mas que passa por ali, sendo motivado pela interação entre outros dois espaços.

Portanto, enquanto a Integração mede a proximidade entre um espaço e todos os outros, a Escolha mensura sua centralidade em relação aos outros pares de espaço 
do sistema, ou o quanto ela é capaz de intermediar o movimento entre espaços ${ }^{1}$.

Essas medidas podem ser calculadas utilizando um determinado raio fixo, também topológico, chamado de raio local, o qual, no caso da medida de Integração, mede o quão próxima (topologicamente) essa linha está em relação ao seu entorno imediato. 0 raio local mais utilizado é igual a 3 (R3), mas também pode ser 5, 7, 9 ou qualquer outro número desejado. Segundo Vargas (2003), muitos trabalhos usam Integração R3 por indicar a condição de integração e segregação local, aproximadamente na escala do bairro.

Aplicadas ao tema deste estudo, Integração e Escolha podem auxiliar a esclarecer as preferências de localização dos produtores imobiliários de edificações verticais em relação a esses dois aspectos e, dessa forma, auxiliar a testar as hipóteses delineadas para o trabalho. Para tornar a leitura mais fácil, em alguns momentos ao se referir aos efeitos combinados de Integração e Escolha, usa-se o termo "acessibilidade", ressaltando que, aqui, ele diz respeito apenas à acessibilidade configuracional, isto é, àquela proporcionada exclusivamente pela malha.

\section{Procedimentos metodológicos}

Para testar as hipóteses, identificaram-se os ERVs a partir de três pavimentos ${ }^{2}$ construídos entre as décadas de 1950 e 2000 em Florianópolis, totalizando 2.064 unidades, conforme base de dados do cadastro imobiliário

\footnotetext{
${ }^{1}$ Apesar de semelhantes, essas medidas captam propriedades diferentes da localização de um espaço em relação a todos os outros. Como exemplo, considere uma rua sem saída localizada no centro de um aglomerado urbano. Sua Integração (proximidade a outras linhas) será alta, enquanto que sua Escolha será igual a 0 (não faz parte de nenhum caminho, não realiza nenhuma ligação entre espaços). Mais especificamente em Florianópolis, com seu tecido altamente descontínuo e segregado, a correlação entre ambas as medidas é praticamente nula $(r=0,089)$.

${ }^{2}$ Para o desenvolvimento desta pesquisa, foram consideradas como edificações verticais aquelas que possuem a partir de três pavimentos. Em Florianópolis, o limite dos gabaritos de altura das edificações é relativamente baixo em relação às demais capitais brasileiras, portanto optou-se por investigar desde três pavimentos, mesmo não correspondendo ao que é normalmente considerado na literatura como edifício vertical. Isso também permitiu a análise por classes diferentes de número de pavimentos, o que trouxe entendimentos adicionais.
}

da Prefeitura Municipal. A análise sintático-espacial das vias em que os ERVs estão localizados foi feita de acordo com os mapas axiais da área conurbada de Florianópolis, que possui 19.276 linhas. A lógica de localização dos ERVs foi investigada em quatro recortes de estudo: Sede Continente, Sede Ilha ${ }^{3}$, Centro e Balneários (Cachoeira do Bom Jesus, Campeche, Canasvieiras e Ingleses), conforme Figura 1.

Os ERVs foram sistematizados segundo a década de construção (1950 a 2000) e o número de pavimentos (3 a 4; 5 a 8; 9 a 12; e 13 a 18).

Em seguida, as médias das medidas sintáticas de Integração e Escolha (global e local) das vias em que os ERVs estão presentes foram comparadas com as médias do sistema como um todo ${ }^{4}$, para identificar quais as propriedades configuracionais dessas vias. Isso permitiu testar duas possibilidades: caso os promotores responsáveis pela produção de ERVs não possuíssem nenhuma preferência quanto à localização desses empreendimentos (no que diz respeito às categorias de proximidade e intermediação), então era de se esperar que as médias sintáticas das vias em que eles estavam localizados fossem aproximadamente similares às do sistema como um todo. Nesse caso, a distribuição seria aproximadamente aleatória em relação a esses aspectos. No entanto, caso essas preferências existissem, as médias das vias em que os ERVs estavam localizados deveriam ser diferentes do resto do sistema: por exemplo, se os empreendedores preferissem locais mais próximos do resto do sistema, como a teoria prevê, a média da Integração das vias em que eles estavam localizados deveria ser maior do que a média do sistema como um todo.

Para a leitura das características sintático-espaciais por década de construção e número de pavimentos, utilizaram-se as médias dos valores de Integração e Escolha para cada linha axial, ponderadas pela quantidade de ERV em cada uma delas. Nesses casos,

\footnotetext{
${ }^{3}$ No recorte Sede Ilha, está incluída a análise do bairro Centro, cujo recorte também foi analisado separadamente por se tratar de uma área de alta concentração de edificações verticais.

${ }^{4}$ Para evitar distorções, foram consideradas, nas médias do sistema como um todo, apenas as vias localizadas em zonas do Plano Diretor que permitem edificações com três ou mais pavimentos. Sem esse cuidado, seria possível comparar com áreas em que os ERVs não apareceram exclusivamente por causa de uma limitação legal.
} 

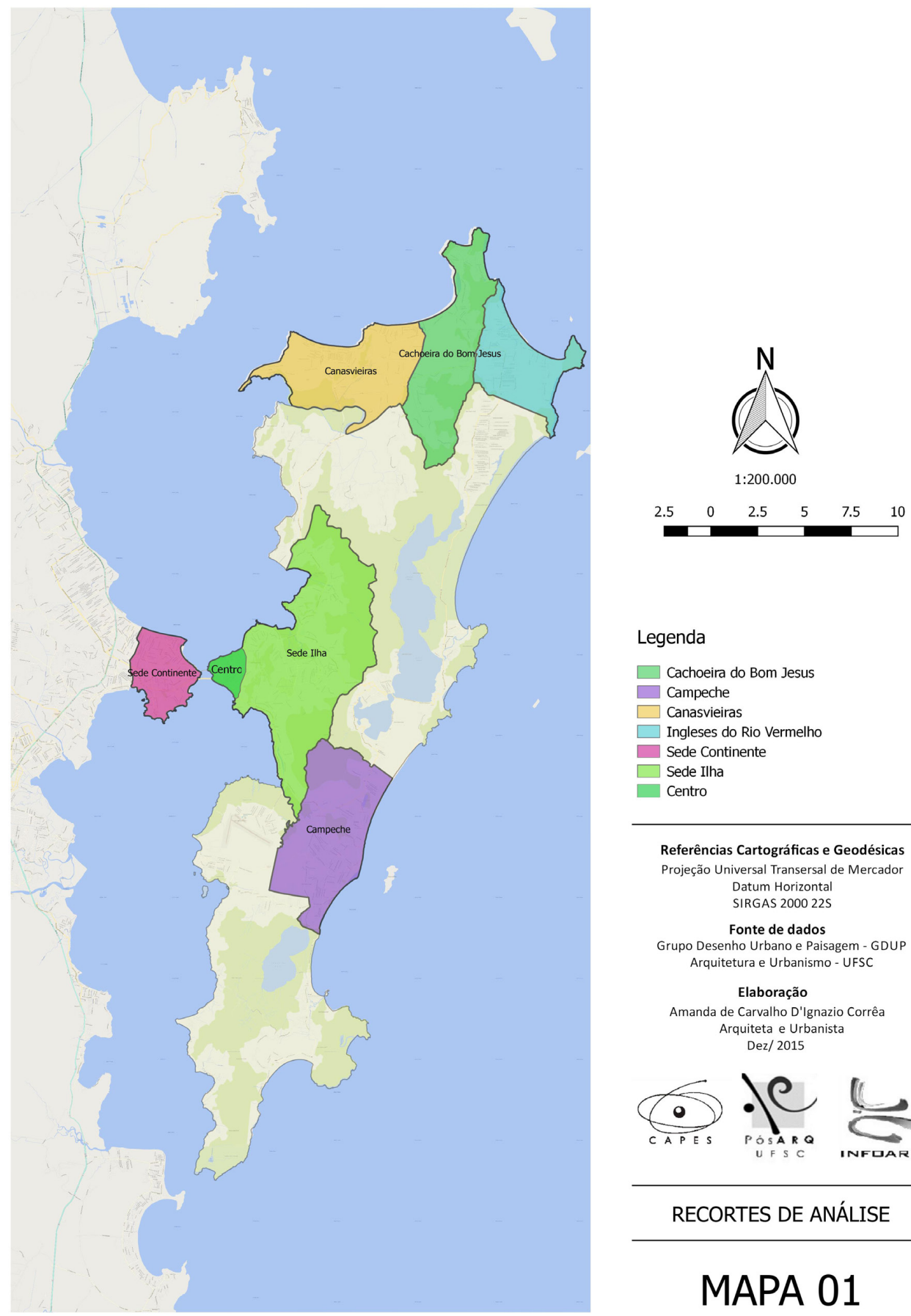

Legenda

$\square$ Cachoeira do Bom Jesus

$\square$ Campeche Canasvieiras

Ingleses do Rio Vermelho

- Sede Continente

$\square$ Sede Ilha

Centro

Referências Cartográficas e Geodésicas

Projeção Universal Transersal de Mercador Datum Horizontal SIRGAS 2000225

Fonte de dados Grupo Desenho Urbano e Paisagem - GDUP Arquitetura e Urbanismo - UFSC

Elaboração

Amanda de Carvalho D'Ignazio Corrêa Arquiteta e Urbanista Arquiteta e Urb 2015
Dez/

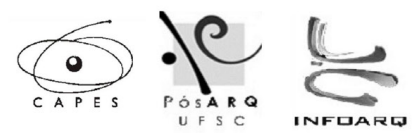

RECORTES DE ANÁLISE

\section{MAPA 01}

Figura 1 - Recorte de análise: Sede Continente, Sede Ilha, Centro e Balneários Fonte: Prefeitura Municipal de Florianópolis (PMF) (IPUF, 2012).

foram produzidas tabelas contendo as médias sintáticas (Integração Rn e R3 e Escolha Rn e R3) gerais de cada recorte e a média sintática ponderada pela quantidade de ERV em suas respectivas linhas axiais. Tal procedimento visou proporcionar maior fidelidade às medidas obtidas, uma vez que, se isso não fosse feito, vias com diferentes quantidades de ERVs (por exemplo, 1 ERV em uma via e 20 em outra) acabariam sendo contabilizadas de forma igual.

A seguinte fórmula descreve esse procedimento: 
$M p=\frac{\sum_{i=0}^{n} m s_{i} \times q e_{i}}{q t e}$

Em que: Mp é a média ponderada da medida sintática; n é o número total de linhas axiais no recorte; $\mathrm{ms}_{\mathrm{i}}$ é a medida sintática para a linha axial $i$ (Integração ou Escolha, local ou global); qe é a quantidade de ERVs na linha axial $i$; qte é a quantidade total de ERVs no recorte.

A partir dessas informações, fez-se a comparação das características sintáticas das vias com ERVs e o conjunto das vias como um todo, tentando compreender se havia diferenças significativas, em termos de proximidade e centralidade, entre as vias em que os ERVs foram construídos e as demais vias do sistema urbano. Foram incluídas também análises desagregadas por décadas e por classes de números de pavimentos, para identificar nuances no comportamento da localização dessas edificações segundo esses aspectos.

\section{Florianópolis: breve contextualização}

\section{Processo de expansão urbana de Florianópolis}

Capital de Santa Catarina, Florianópolis, no início do século XX, era uma cidade provinciana e sua estrutura fundiária resumia-se ao atual centro histórico e à porção continental. No entanto, diversas modificações urbanas tiveram início graças à construção civil, responsável por novos investimentos (Campos, 2009).

A integração entre continente e ilha era feita por meio de balsas e ferry boats. Com a construção da Ponte Hercílio Luz em 1926, houve alteração na dinâmica da cidade não somente em relação ao transporte, agora mais ágil, mas, principalmente, pela relação comercial (Bortoluzzi, 2004).

A instalação de diversos órgãos do governo nos anos de 1960, principalmente a Universidade Federal de Santa Catarina, atraiu um significativo crescimento e desenvolvimento para a cidade e, consequentemente, para a expansão urbana do município. Na segunda metade da década de 1960, com crescimento lento, porém, definitivo, teve início a expansão vertical no centro da cidade (Campos, 2009).

A construção da BR-101, na década de 1970, tornou os deslocamentos mais rápidos, incentivando, segundo Coelho (2012), o processo de implantação das rodovias estaduais, principalmente a SC-401, que ligava o centro ao Balneário Canasvieiras, facilitando o acesso às praias e dinamizando a cidade. A construção das novas pontes, Colombo Machado Sales e Pedro Ivo Campos, além dos aterros norte e sul, propiciaram a expansão urbana, assim como os viadutos, as ruas e as vias duplas construídas pela ilha. Na década de 1970, Florianópolis experimentou seu primeiro boom imobiliário. Surgiram os primeiros grandes empreendimentos residenciais, implantados no centro da cidade, na Avenida Beira-Mar Norte e próximo ao bairro Trindade.

Segundo Campos (2009), na década de 1980, algumas grandes construtoras deram lugar às de menor porte. Assim, os novos edifícios, que antes se concentravam no centro da cidade e possuíam em média 12 pavimentos, nesse novo cenário migraram para bairros periféricos e passaram a ser construídos com até quatro pavimentos, iniciando a expansão horizontal do município.

A partir dos anos de 2000, ocorreu na Região Metropolitana de Florianópolis uma grande "explosão imobiliária". A cidade passou a ser um sonho de consumo para diversas classes sociais, tanto nacionais quanto internacionais, atraindo, principalmente, pessoas vindas dos Estados do Rio Grande do Sul, Paraná e São Paulo, além de países vizinhos, em busca de qualidade de vida. Esse cenário acabou por impulsionar ainda mais a indústria da construção civil, colaborando para uma grande expansão urbana, que deu início a uma verticalização generalizada da cidade.

\section{Resultados}

Análise sintática-espacial da localização dos ERVs em Florianópolis

A localização dos ERVs em Florianópolis foi investigada em sete recortes da cidade: Sede Continente, Sede Ilha, Centro, Balneário Cachoeira do Bom Jesus, Balneário Campeche, Balneário Canasvieiras e Balneário Ingleses.

A primeira análise trata-se de uma verificação visual obtida por meio dos mapas sintáticos de Integração e Escolha em escala Rn (global) e R3 (local). Por meio dela, é possível ver que, no Distrito Sede Continente, Sede Ilha e Centro, a localização dos ERVs ocorre em vias com alta Integração Rn, no entanto com média a baixa Escolha Rn, ou seja, os ERVs estão em vias que tornam sua localização relativamente próxima às diversas áreas da cidade. Contudo, essas mesmas vias, 
apesar de estarem próximas, em média, do restante dos espaços, não tendem a ser utilizadas como os principais caminhos para esses outros espaços.

Localmente, os ERVs foram implantados em vias com alta Integração R3, porém de média a alta Escolha R3. Isso significa que os ERVs estão localizados em vias que os deixam próximos de todos os espaços dentro do bairro e, adicionalmente, são utilizados como passagem para esses espaços.

Também foi identificada certa tendência de concentração dos ERVs no recorte Centro em sua porção localizada mais ao norte. Isso ocorre, provavelmente, por questões históricas mais do que por motivos configuracionais, uma vez que a área ao sul corresponde ao Centro Histórico do Município, com grande quantidade de edificações históricas preservadas. Essas análises podem ser visualizadas na Figura 2.

Nos Balneários de Florianópolis, encontra-se outro padrão de localização. Os ERVs estão implantados em vias altamente segregadas e de média a baixa Escolha Rn, ou seja, eles estão em vias consideradas afastadas das demais áreas da cidade e também pouco

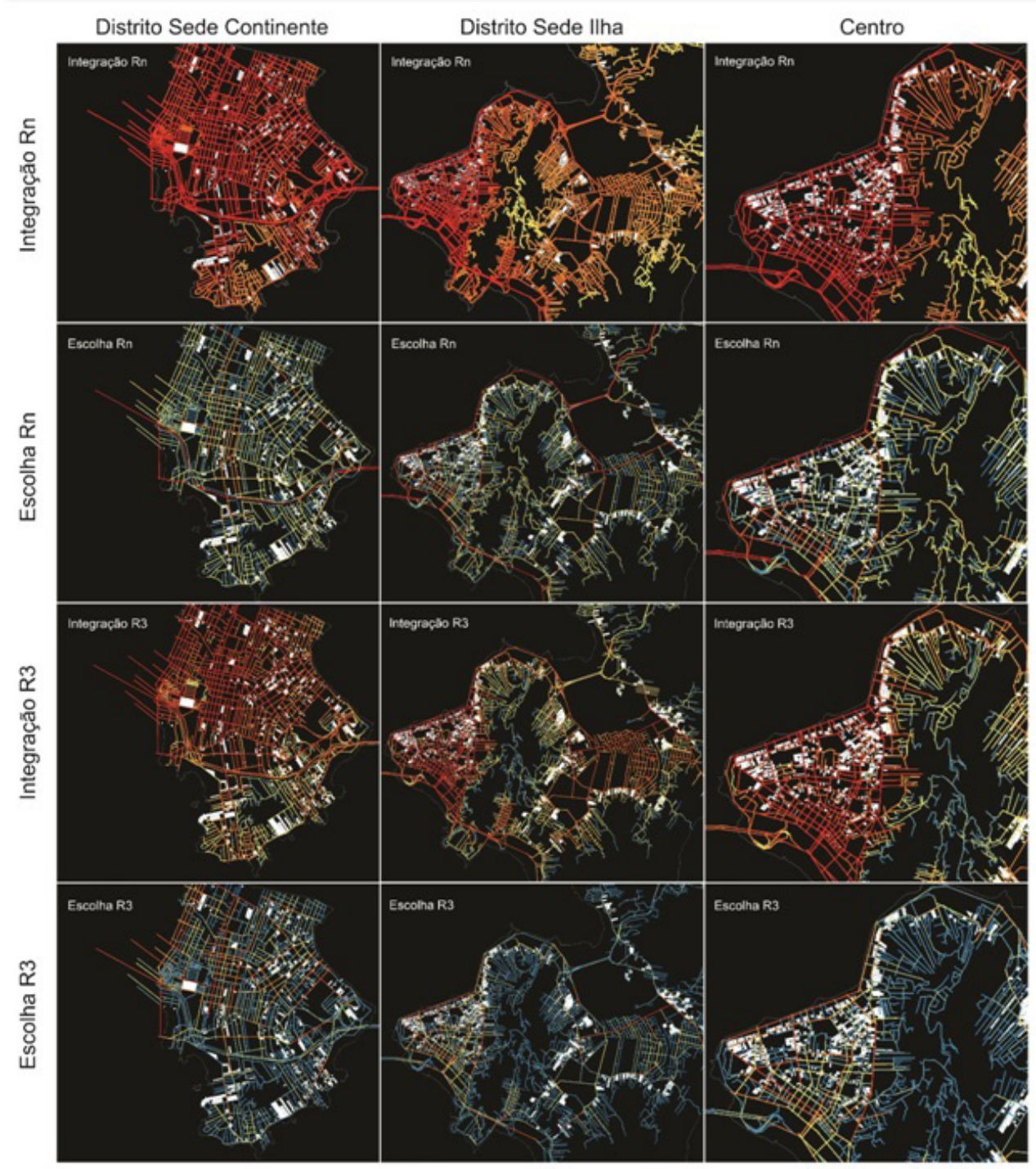

\section{Legenda}

Mais Segregada | Menor Escolha

Mais Integrada | Maior Escolha

Figura 2 - Mapas de Integração e Escolha Rn e R3: Distrito Sede Continente, Sede llha e Centro Fonte: Elaborado pelos autores. 
utilizadas como passagem para outros locais, como mostra a Figura 3.

Em escala local, os ERVs estão localizados em vias com média Integração R3, porém, com relação à Escolha R3, não é possível identificar um padrão claro, sendo encontrados ERVs em áreas de alta e baixa Escolha local nos recortes. Nos Ingleses, Campeche e Cachoeira do Bom Jesus, a ampla maioria dos ERVs situa-se em vias com baixa Escolha R3, enquanto que, em Canasvieiras, podem-se encontrar ambas as situações. Nesse ponto, fica claro que os ERVs nos Balneários se orientam muito mais segundo a lógica de proximidade à orla do que o ponto de vista puramente configuracional.
Análise sintática-espacial da localização dos ERVs em Florianópolis segundo a década de construção

As análises comparativas das médias sintáticas das vias com ERV em cada década de construção, contidas nas Tabelas 1 e 2, mostram que, em todos os recortes do estudo, houve um crescimento significativo da medida de Escolha R3. Ao longo do período analisado, as medidas de Integração (Rn e R3) permaneceram praticamente constantes. Esses resultados indicam que a localização dos ERVs ocorreu em vias relativamente tranquilas, utilizadas como caminhos para as outras áreas dentro do próprio bairro e fora dos acessos globais da cidade.

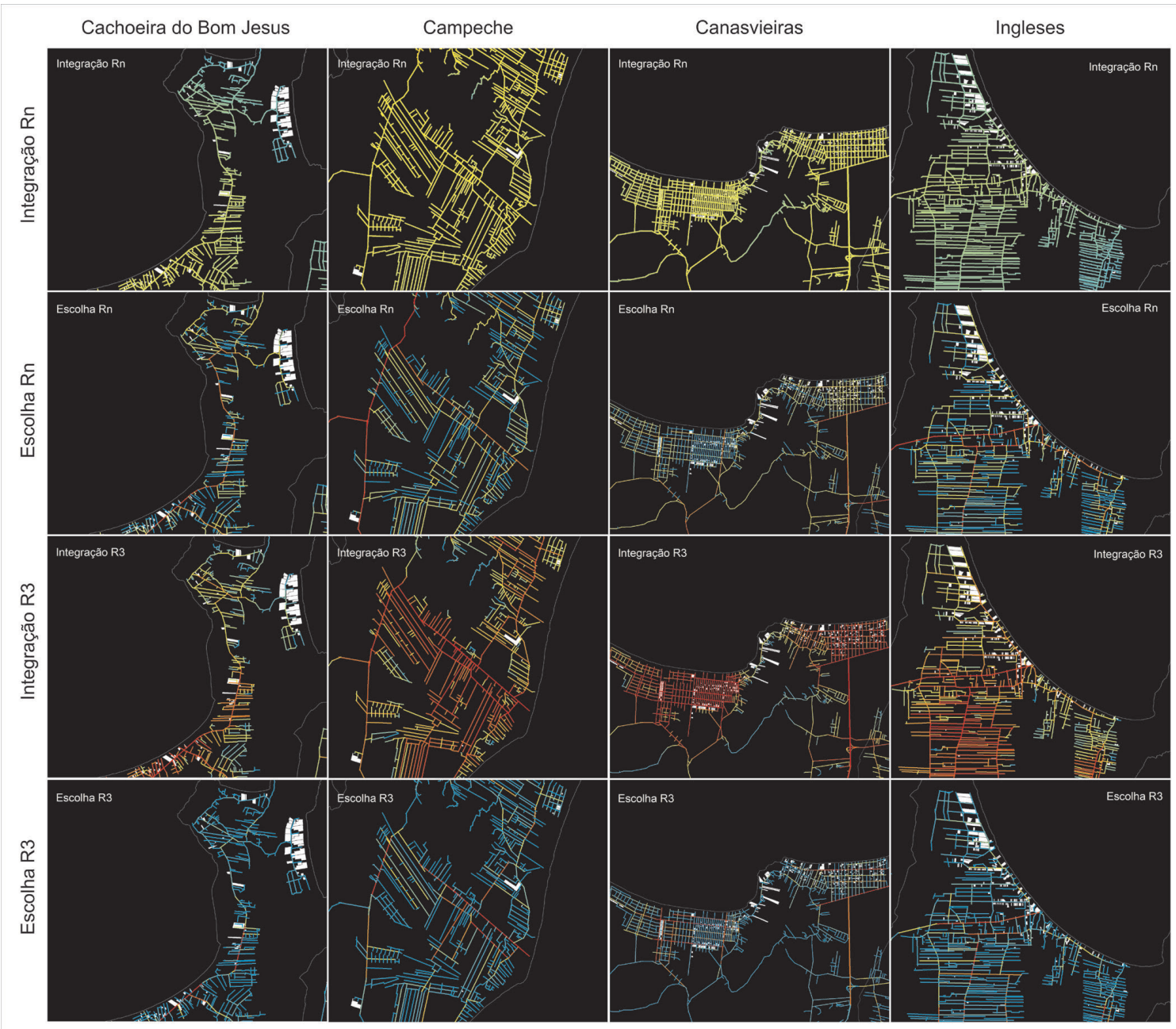

\section{Legenda}

Mais Segregada | Menor Escolha

Mais Integrada | Maior Escolha

Figura 3 - Mapas de Integração e Escolha Rn e R3: Balneários

Fonte: Elaborado pelos autores. 
Tabela 1 - Médias Rn das medidas sintáticas, década de construcũõo e médias ponderadas

\begin{tabular}{|c|c|c|c|c|c|c|c|c|}
\hline & \multicolumn{2}{|c|}{ Sede Cont } & \multicolumn{2}{|c|}{ Sede llha } & \multicolumn{2}{|c|}{ Centro } & \multicolumn{2}{|c|}{ Balneários } \\
\hline & Int Rn & Esc Rn & $\operatorname{lnt} \mathbf{R n}$ & Esc $\mathbf{R n}$ & Int Rn & Esc Rn & $\operatorname{lnt} \mathbf{R n}$ & Esc Rn \\
\hline Geral & 0,27 & $2.516 .115,14$ & 0,23 & $2.883 .950,86$ & 0,26 & $3.447 .193,31$ & 0,16 & $1.552 .055,36$ \\
\hline \multicolumn{9}{|c|}{ Médias para as vias com ERVs (ponderadas) } \\
\hline 1950 & - & - & 0,29 & $4.149 .727,50$ & 0,29 & 4.149.727,50 & - & - \\
\hline 1960 & 0,28 & $2.857 .822,88$ & 0,28 & $10.115 .368,14$ & 0,28 & $10.115 .368,14$ & - & - \\
\hline 1970 & 0,27 & $1.997 .377,35$ & 0,28 & 25.231.920,24 & 0,28 & $30.859 .340,90$ & 0,16 & $849.141,80$ \\
\hline 1980 & 0,27 & $1.095 .603,00$ & 0,26 & $14.481 .949,09$ & 0,28 & $24.883 .890,88$ & 0,15 & $2.336 .971,46$ \\
\hline 1990 & 0,24 & $1.659 .573,55$ & 0,26 & $12.330 .652,93$ & 0,28 & $24.287 .497,64$ & 0,16 & $1.404 .787,00$ \\
\hline 2000 & 0,27 & $1.759 .382,41$ & 0,26 & $8.103 .637,05$ & 0,28 & 24.659.641,91 & 0,16 & $1.369 .876,83$ \\
\hline
\end{tabular}

Fonte: Elaborado pelos autores.

Tabela 2 - Médias R3 das medidas sintáticas, década de construcũão e médias ponderadas

\begin{tabular}{|c|c|c|c|c|c|c|c|c|}
\hline & \multicolumn{2}{|c|}{ Sede Cont } & \multicolumn{2}{|c|}{ Sede Itha } & \multicolumn{2}{|c|}{ Centro } & \multicolumn{2}{|c|}{ Balneários } \\
\hline & Int R3 & Esc R3 & Int R3 & Esc R3 & Int R3 & Esc R3 & Int R3 & Esc R3 \\
\hline Geral & 1,25 & 63,11 & 0,94 & 28,36 & 1,1 & 51,47 & 1,01 & 33,3 \\
\hline \multicolumn{9}{|c|}{ Médias para as vias com ERVs (ponderadas) } \\
\hline 1950 & - & - & 1,62 & 293,50 & 1,62 & 293,50 & - & - \\
\hline 1960 & 1,37 & 70,75 & 1,56 & 355,57 & 1,56 & 355,57 & - & - \\
\hline 1970 & 1,32 & 175,48 & 1,50 & 319,11 & 1,58 & 371,14 & 1,31 & 185,70 \\
\hline 1980 & 1,37 & 169,92 & 1,39 & 219,20 & 1,60 & 349,56 & 1,23 & 154,38 \\
\hline 1990 & 1,36 & 195,31 & 1,32 & 197,10 & 1,58 & 364,01 & 1,37 & 159,20 \\
\hline 2000 & 1,35 & 170,03 & 1,19 & 118,28 & 1,54 & 284,10 & 1,39 & 196,35 \\
\hline
\end{tabular}

Fonte: Elaborado pelos autores.

Destaca-se nesta análise que, no recorte Sede Ilha, a média de Escolha Rn e R3 apresentou queda a partir da década de 1980. Especificamente na década de 1970, há um crescimento significativo na média de Escolha Rn, associado ao período em que começaram a ser implantados ERVs ao longo da Avenida Beira-Mar Norte, principal acesso ao norte da ilha e com alto índice de Escolha Rn. Esse decréscimo observado nos valores de Escolha indica que houve uma migração na preferência da localização dos ERVs, passando de vias com altos valores de escolha e indo para vias localizadas fora dos caminhos de passagens em nível global e local. Esse fenômeno provavelmente tem relação com a escassez de terrenos ao longo do tempo em vias de alta escolha, ilustrando o mecanismo de equilíbrio entre a acessibilidade da localização e o custo do terreno, citado anteriormente.

Inicialmente, essa equação favorecia os terrenos localizados nas vias mais Integradas e de mais alta Escolha, nas quais a localização era boa (configuracionalmente) e o custo da terra não inviabilizava o negócio. A partir de um determinado momento, entretanto, esses locais provavelmente passaram a oferecer obstáculos para a construção de ERVs, tanto pela dificuldade em encontrar terrenos apropriados quanto pelo custo mais alto da terra, circunstâncias definidas pelo processo histórico de ocupação recente e intimamente ligadas entre si. Assim, a equação entre acessibilidade e custo passou a favorecer locais menos integrados e com Escolha mais baixa, indicando uma tendência atual de instalação desses empreendimentos em vias mais locais onde o 
custo da terra é menor, fora dos principais fluxos de passagem e em locais mais interiorizados no tecido.

Percebe-se que, ainda que os valores sintáticos tenham mostrado uma queda a partir da década de 1970, eles ainda se mantêm maiores do que a média do sistema como um todo. Isso sugere que, dentre um conjunto de localizações consideradas adequadas à implementação de um ERV (aquelas com melhor acessibilidade), o empreendedor procura aquelas mais baratas (as piores entre as melhores) para maximizar seu lucro.

Outro padrão encontrado foi um crescimento da média de Escolha Rn na década de 1980 no recorte Balneário. Esse resultado coincide com o período de expansão imobiliária e indica que os ERVs se localizavam nas vias de acesso principal desses recortes. Após esse período, a Escolha Rn diminuiu. Nessa área, as médias de Escolha R3 apresentaram crescimento em todos os períodos estudados, indicando que, embora os ERVs estivessem em vias segregadas na escala do todo do sistema, essas vias eram geralmente utilizadas como caminhos para as outras áreas dentro do próprio bairro. Portanto, complementando a análise visual anterior, vê-se que as vias junto à orla são, também, aquelas com maior escolha local do que a média do sistema.

Análise sintática-espacial da localização dos ERVs em Florianópolis segundo o número de pavimentos

A localização dos ERVs também foi analisada de acordo com o número de pavimentos de cada edificação.

A partir da comparação das médias de Integração e Escolha (Rn e R3) para cada grupo conforme o número de pavimentos, contidas nas Tabelas 3 e 4, vê-se que, em todos os recortes de estudo, independentemente do número de pavimentos, a medida mais significativa para identificação das características sintáticas da localização foi a Escolha R3. Houve um crescimento relevante da média dessa medida conforme foi aumentando o número de pavimentos.

Tabela 3 - Médias Rn das medidas sintáticas, número de pavimentos e médias ponderadas

\begin{tabular}{|c|c|c|c|c|c|c|c|c|}
\hline & \multicolumn{2}{|c|}{ Sede Cont } & \multicolumn{2}{|c|}{ Sede Ilha } & \multicolumn{2}{|c|}{ Centro } & \multicolumn{2}{|c|}{ Balneários } \\
\hline & $\ln \mathbf{R n}_{\mathbf{n}}$ & Esc Rn & Int $\mathbf{R n}$ & Esc Rn & $\ln t \mathbf{R n}$ & Esc $\mathbf{R n}$ & Int $R \mathbf{n}$ & Esc $\mathbf{R n}$ \\
\hline Geral & 0,27 & $2.516 .115,14$ & 0,23 & $2.883 .950,86$ & 0,26 & $3.447 .193,31$ & 0,16 & $1.552 .055,36$ \\
\hline \multicolumn{9}{|c|}{ Médias para as vias com ERVs (ponderadas) } \\
\hline 03-04 Pavtos & 0,27 & $1.726 .906,15$ & 0,25 & $2.667 .959,38$ & 0,28 & $6.319 .357,02$ & 0,16 & $1.401 .086,77$ \\
\hline 05-08 Pavtos & 0,27 & $1.180 .436,23$ & 0,24 & $3.888 .800,50$ & 0,28 & $14.033 .094,04$ & 0,16 & $1.707 .363,96$ \\
\hline 09-12 Pavtos & 0,27 & $1.745 .301,29$ & 0,27 & $23.285 .182,12$ & 0,28 & $14.974 .042,12$ & - & - \\
\hline 13-18 Pavtos & 0,28 & $454.755,63$ & 0,28 & $30.097 .628,47$ & 0,28 & $12.101 .567,68$ & - & - \\
\hline
\end{tabular}

Fonte: Elaborado pelos autores.

Tabela 4 - Médias R3 das medidas sintáticas, número de pavimentos e médias ponderadas

\begin{tabular}{|c|c|c|c|c|c|c|c|c|}
\hline & \multicolumn{2}{|c|}{ Sede Cont } & \multicolumn{2}{|c|}{ Sede Ilha } & \multicolumn{2}{|c|}{ Centro } & \multicolumn{2}{|c|}{ Balneários } \\
\hline & Int R3 & Esc R3 & Int R3 & Esc R3 & Int R3 & Esc R3 & Int R3 & Esc R3 \\
\hline Geral & 1,25 & 63,11 & 0,94 & 28,36 & 1,1 & 51,47 & 1,01 & 33,3 \\
\hline \multicolumn{9}{|c|}{ Médias para as vias com ERVs (ponderadas) } \\
\hline 03-04 Pavtos & 1,35 & 188,64 & 1,21 & 96,49 & 1,53 & 219,35 & 1,35 & 145,96 \\
\hline 05-08 Pavtos & 1,36 & 137,18 & 1,18 & 120,48 & 1,57 & 412,02 & 1,50 & 367,64 \\
\hline 09-12 Pavtos & 1,40 & 178,65 & 1,47 & 292,10 & 1,59 & 367,78 & - & - \\
\hline 13-18 Pavtos & 1,48 & 268,75 & 1,55 & 354,33 & 1,59 & 388,86 & - & - \\
\hline
\end{tabular}

Fonte: Elaborado pelos autores. 


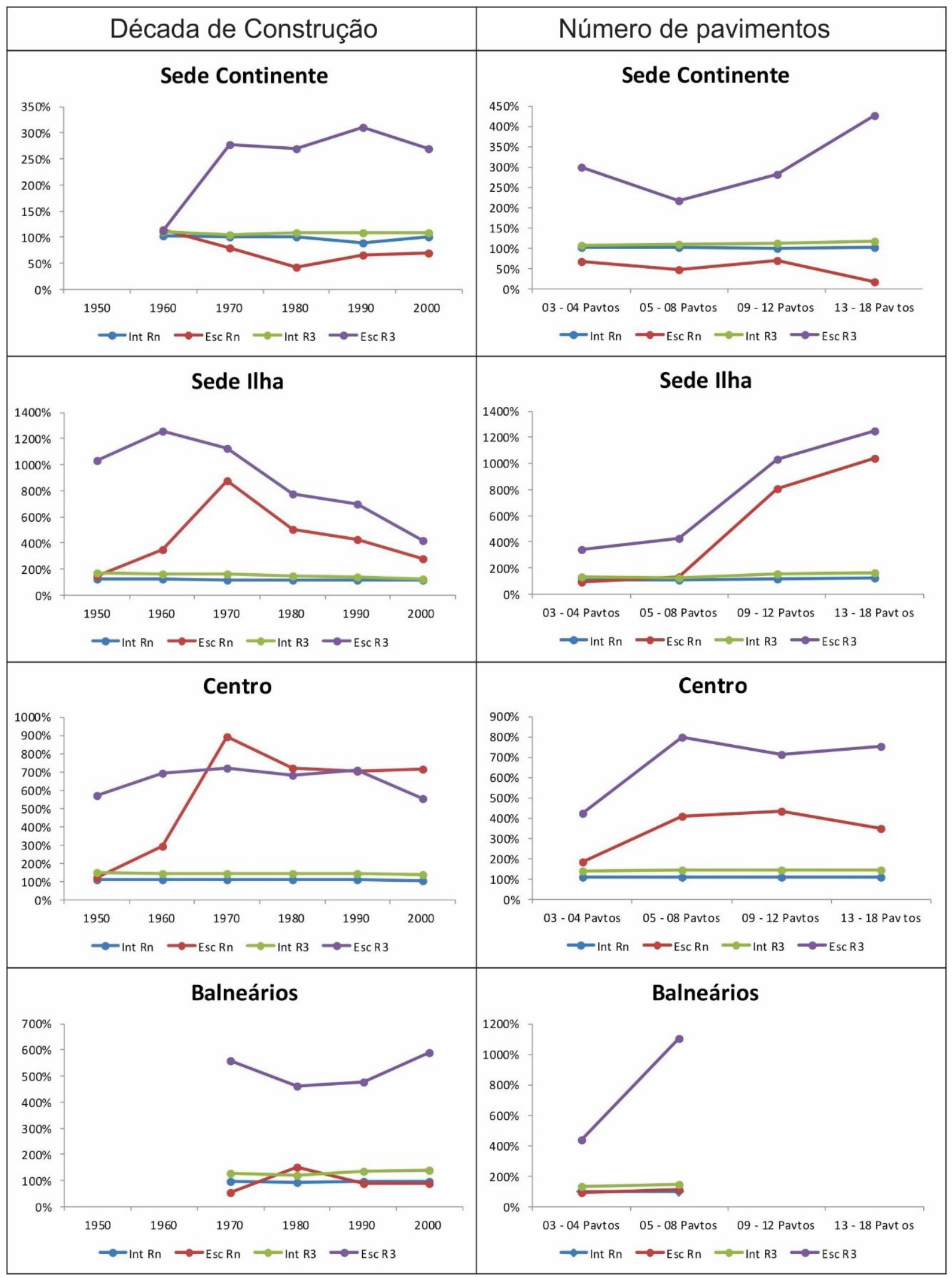

Gráfico 1 - Médias ponderadas de Integração e Escolha (Rn/R3) em relação à média do recorte (100\%) Fonte: Elaborado pelos autores. 
Houve um padrão de crescimento significativo da Escolha Rn (embora menor que o crescimento da Escolha R3) no recorte Sede Ilha. Assim como no caso da Escolha R3, as médias para Escolha Rn também aumentaram conforme crescia o número de pavimentos. Isso faz sentido, uma vez que, conforme mencionado anteriormente, vias com maior acessibilidade tendem a possuir valores mais altos do solo e isso, por sua vez, conduz a uma intensificação do aproveitamento do solo por meio do aumento da relação entre a área construída e a área do terreno. Assim, edificações mais altas tendem a aparecer em vias com maior Integração e Escolha do que edificações mais baixas, ainda que sujeitas às limitações introduzidas pelo processo histórico de ocupação, como ficou evidenciado no item anterior. Nesses casos, essa intensificação do uso do solo pelo potencial construtivo pode também ser um fator que possibilite que os ERVs vençam a disputa por essas localizações com outros usos, especialmente comércios e serviços.

Verificou-se também que, na Sede Continente, houve diminuição da média ponderada de Escolha Rn em relação à média geral do recorte para todas as análises de gabarito. Essa diminuição se deve, principalmente, ao fato de os ERVs estarem fora das rotas de acesso global, que nesse recorte constituem-se em grande parte por vias exclusivamente de passagem, à semelhança de rodovias, sem usos e edificações abrindo-se para elas.

Quanto às medidas de Integração, os ERVs, exceto os localizados nos Balneários, estão em vias altamente integradas em escala global. Localmente, essa medida é alta para todos os gabaritos dos recortes de análise.

\section{Comparação entre o comportamento por décadas e o número de pavimentos}

O Gráfico 1 mostra o comportamento (crescimento ou queda em relação à média do recorte, representada pelo valor $100 \%$, em cada caso) das médias ponderadas de Integração e Escolha (Rn e R3) em porcentagem.

É possível identificar que, em todos os recortes, analisando os ERVs tanto por década de construção quanto por número de pavimentos, houve grande destaque para a medida de Escolha R3. Os resultados mostraram que, embora a legislação tenha possibilitado o processo de verticalização em diversas vias da cidade, os empreendedores implantaram suas edificações preferencialmente em vias de alto fluxo de passagem local (Escolha R3). A integração e a segregação desses ERVs mostraram-se como um fator secundário, considerando especialmente $o$ caso dos Balneários.

\section{Conclusões}

São inúmeras as características relacionadas à escolha de determinada localização, por exemplo, questões socioeconômicas, culturais, simbólicas, de valor do solo, de acesso a bens e serviços etc. Porém, este artigo baseou-se na busca pela identificação da lógica locacional sob a ótica configuracional, ou seja, entender se e como o modo pelo qual cada via se relaciona com todas as outras do sistema ou de seu entorno imediato influencia a localização dos ERVs em Florianópolis ou, ao menos, pode dar pistas sobre as localizações preferidas pelos empreendedores para instalar esse tipo de edificação.

Para essa análise configuracional, foi utilizada a Sintaxe Espacial, que permitiu medir duas importantes propriedades: Integração, que possibilitou identificar o quão próximo um ERV está de todos os outros espaços do sistema, e Escolha, que indicou o quanto esse ERV está localizado na passagem entre os demais espaços da cidade. 0 mesmo raciocínio foi aplicado para análises locais, restringindo a um raio limitado (R3) e considerando apenas os espaços dentro desse raio de abrangência. Comparando essas duas análises, foi possível identificar se os ERVs concentram-se em vias mais ou menos integradas, ou em vias com maior ou menor Escolha.

A localização dos ERVs foi analisada segundo a década de construção e o número de pavimentos, relacionando a média geral dos recortes e a média ponderada pelo número de ERVs em cada via.

Em geral, a chave encontrada para o entendimento da localização dos ERVs em Florianópolis está relacionada à medida de Escolha local (R3), ou seja, há maior concentração de ERVs em vias que canalizam fluxos utilizados para chegar às outras partes dentro de um sistema local.

No recorte Sede Continente, chama atenção o comportamento da Escolha Rn, que aparece sempre abaixo da média do sistema. Nesse recorte, a localização dos ERVs ocorreu sempre em vias que não fazem parte dos caminhos de acesso global, preferindo vias locais. 
O padrão encontrado no recorte Sede Ilha confirma os resultados apontados anteriormente. Com o decorrer do tempo, uma possível escassez dos terrenos em vias de alto índice de escolha, tanto Rn quanto R3, fez com que houvesse uma redução dessas médias, já que os ERVs passaram, a partir da década de 1980, a se localizar em vias com menores índices de Escolha (Rn e R3). Sobre sua relação com o número de pavimentos, quanto maior sua medida de Escolha R3, mais alta é a edificação. A média de Escolha R3 também apresentou grande destaque dentre as demais medidas nos Balneários.

Em relação às médias de Integração Rn e R3, estas permaneceram aproximadamente constantes em todos os recortes, independentemente da década de construção ou número de pavimentos.

Em suma, as conclusões alcançadas por este estudo podem ser sintetizadas nos seguintes pontos:

a) Em geral, a distribuição dos ERVs possuiu alta Integração Rn e R3, com exceção dos ERVs localizados nos Balneários, que globalmente estavam segregados. Destacaram-se vias de alta Escolha Rn nos recortes Sede Ilha e Centro; já os demais recortes permaneceram com baixos índices para essa medida.

b) A medida de Escolha R3 mostrou-se a mais capaz de diferenciar as localizações das ERVs em relação às demais vias do sistema em que seria possível verticalizar segundo o zoneamento municipal, bem como permitiu fazer distinções por década e por número de pavimentos.

c) Edificações com maior número de pavimentos mostraram médias de Escolha correspondentemente mais altas, refletindo, possivelmente, a necessidade de intensificação da ocupação por causa dos maiores custos da terra decorrentes de localizações em vias de passagem mais intensa (especialmente no nível local).

d) Ao longo das décadas, as localizações buscaram, inicialmente, áreas mais integradas e com maior Escolha, até um determinado momento em que essas medidas atingiam um valor máximo; depois disso, iniciaram um processo de queda e posterior "interiorização" dos ERVs, caracterizada pela busca por vias com menor escolha, mais distantes das principais vias estruturadoras da localidade. e) A década em que ocorreu o pico de acessibilidade variou de recorte para recorte, dependendo do seu processo histórico de ocupação e consolidação áreas mais antigas atingiram na década de 1970 e estão em pleno processo de busca por vias mais interiorizadas, com Escolha Local mais alta que a média, mas em declínio em relação ao passado recente; áreas mais recentes ainda estão investindo nas vias de alta Escolha Local.

f) Como os gradientes de integração mudam muito gradativamente no espaço, essa medida é um bom indicador das áreas gerais da cidade que tendem a despertar o interesse dos empreendedores para a instalação de ERV. Entretanto, dentro de cada área mais local, somente a medida de escolha foi capaz de diferenciar vias muito próximas umas às outras e, por isso, conseguiu descrever de maneira mais precisa a busca pela maximização dos lucros por meio do equilíbrio entre boa acessibilidade e baixo custo.

Esses resultados indicam que é necessário um entendimento mais adequado da lógica de localização dos empreendimentos residenciais verticais para que os instrumentos de controle do uso e ocupação possam dialogar com essa lógica e incorporá-la na orientação do desenvolvimento urbano. 0 que se vê, muitas vezes, é o oposto: em Florianópolis, por exemplo, ficou claro que existem áreas em que a construção em altura é permitida pela legislação, mas que, locacionalmente, não são interessantes para os empreendedores imobiliários ou para os usuários. Assim, são criadas zonas com a intenção de comportar novas centralidades e intensificação de usos, mas que, ao contrário, permanecem vazias e com baixíssima densidade.

É importante também entender como essa lógica funciona de maneira distinta em áreas já consolidadas e em áreas em consolidação. Dessa forma, os instrumentos urbanísticos podem ser ajustados de acordo com cada situação, ao invés de tentar, como frequentemente acontece, adotar a mesma solução para áreas com características muito diferentes.

\section{Referências}

Abramo, P. (2001). Mercado e ordem urbana: do caos à teoria da localização residencial. Rio de Janeiro: Bertrand.

Batty, M. (2009). Urban modeling (p. 51-58, International Encyclopedia of Human Geography). Oxford: Elsevier. 
Bortoluzzi, S. D. (2004). Características das funções e padrões de uso e ocupação do solo no centro de Florianópolis (SC) (dissertação de mestrado). Universidade Federal de Santa Catarina, Florianópolis.

Campos, É. T. (2009). A expansão urbana na região metropolitana de Florianópolis e a dinâmica da indústria da construção civil (tese de doutorado). Universidade Federal de Santa Catarina, Florianópolis.

Capozza, D. R., \& Helsley, R. W. (1989). The fundamentals of land prices and urban growth. Journal of Urban Economics, 26(3), 295-306. http://dx.doi.org/10.1016/0094-1190(89)90003-X.

Coelho, K. D. S. (2012). A resistência à nova proposta de Plano Diretor apresentada pela Prefeitura Municipal de Florianópolis: uma análise das práticas alternativas de organizar (tese de doutorado). Universidade Federal de Santa Catarina, Florianópolis.

Ferreira, C. D. S. (2006). 0 edifício Sant'Anna e a gênese da verticalização em Campinas. Arquitextos, 78, 1-7.

Giuliano, G., Gordon, P., Pan, Q., \& Park, J. (2010). Accessibility and residential land values: some tests with new measures. Urban Studies, 47(14), 3103-3130. http:// dx.doi.org/10.1177/0042098009359949.

Gonzales, S. F. (1985). A renda do solo urbano: hipóteses de explicação de seu papel na evolução da cidade. In R. Farret, S. Gonzales, F. Holanda, \& M. Kohlsdorf. O espaço da cidade - contribuição à análise urbana. São Paulo: Projeto.

Gorter, C., \& Nijkamp, P. (2001). Location theory. In S. Hanson (Ed.), Encyclopedia of the social sciences (p. 90139019). Amsterdam: Elsevier.

Hillier, B. (2007). Space is the machine. London: Space Syntax.

Hillier, B., \& Hanson, J. (1984). The social logic of space. Cambridge: Cambridge University Press.

Hillier, B., \& Iida, S. (2005). Network and psychological effects in urban movement. Spatial information theory ( $\mathrm{p}$. 475-490). New York: Springer Berlin Heidelberg.

Hillier, B., Penn, A., Hanson, J., Grajewski, T., \& Xu, J. (1993). Natural movement-or, configuration and attraction in urban pedestrian movement. Environment and Planning. B, Planning \& Design, 20(1), 29-66. http://dx.doi.org/10.1068/ b200029.

Instituto de Planejamento Urbano de Florianópolis - IPUF. (2012). Base de dados do Cadastro Imobiliário [CD- ROM]. Florianópolis: IPUF.
Krafta, R. (1994). Modelling intraurban configurational development. Environment \& Planning B, 21(1), 67-67. http://dx.doi.org/10.1068/b210067.

Krafta, R. (1999). Spatial self-organization and the production of the city. Cybergeo: European Journal of Geography. Recuperado em 27 de março de 2013, de http://cybergeo. revues.org/4985.

Lynch, K. (1984). Good city form. Cambridge: MIT Press.

Mendes, C. M. (1992). O edifício no jardim: um plano destruído - a verticalização de Maringá (tese de doutorado). Universidade de São Paulo, São Paulo.

Penn, A., Hillier, B., Banister, D., \& Xu, J. (1998). Configurational modelling of urban movement networks. Environment and Planning. B, Planning \& Design, 25(1), 59-84. http:// dx.doi.org/10.1068/b250059.

Ramires, J. (1997). A verticalização de São Paulo e o cinema: uma nova dimensão no estudo das cidades. Revista Sociedade e Natureza, 9(17), 5-76.

Ramires, J. (2011). 0 processo de verticalização das cidades brasileiras. Boletim Geografico, 16(1), 97-106.

Somekh, N. (1997). A cidade vertical e o urbanismo modernizador. São Paulo: Edusp.

Souza, M. A. A. D. (1994). A identidade da metrópole: a verticalização em São Paulo. São Paulo: Hucitec.

Töws, R. L., \& Mendes, C. M. (2011). 0 estudo da verticalização urbana como objeto da geografia: enfoques e perspectivas metodológicas. In Anais do I Simpósio de Estudos Urbanos (p. 1-25). Campo Mourão: Universidade Estadual do Paraná.

Vargas, J. C. B. (2003). Centros urbanos vitais: configuração, dinâmica funcional e caráter das ruas comerciais de Porto Alegre (dissertação de mestrado). Universidade Federal do Rio Grande do Sul, Porto Alegre.

Villaça, F. (1986). O que todo cidadão precisa saber sobre habitação. São Paulo: Global.

Villaça, F. (2001). Espaço intra-urbano no Brasil. São Paulo: Studio Nobel.

Wheaton, W. C. (1982). Urban spatial development with durable but replaceable capital. Journal of Urban Economics, 12(1), 53-67. http://dx.doi.org/10.1016/0094-1190(82)90004-3.

Recebido: Mar. 28, 2016

Aprovado: Set. 15, 2016 